International Journal of Microelectronics Engineering (IJME), Vol.2, No.2, April 2016

\title{
ANALYSIS AND SIMULATION OF DYNAMIC COMPARATOR USING 180NM AND 90NM TECHNOLOGY
}

\author{
Ratansang S Vaghela and Priyesh P. Ghandhi \\ Electronics and Communication Dept, LCIT, Bhandu, North Gujarat, India.
}

\begin{abstract}
In today's world there is demand of low power and high speed application circuits for the portable devices. To meet this demand dynamic comparator play very important role. It has application mostly in Flash ADC. In my paper, I have Analyzed basic dynamic comparator with different characteristics like Propagation delay, speed, offset, ICMR, slew rate etc. I have used TSMC 180nm and TSMC 90nm technology for simulation and compared woks of both technologies. Finally with optimization of these circuits and comparison of these technologies will helped me in obtaining one circuit which will have low power, low offset and high speed CMOS voltage comparator.
\end{abstract}

\section{KEYWORDS}

Dynamic,Transistor, clock, Technology, mismatch, comparator.

\section{INTRODUCTION}

Dynamic Comparator is one of the basic building blocks in most ADC for application like image sensors, Transceivers etc. Fig 1.Shows the block diagram of Dynamic comparator.

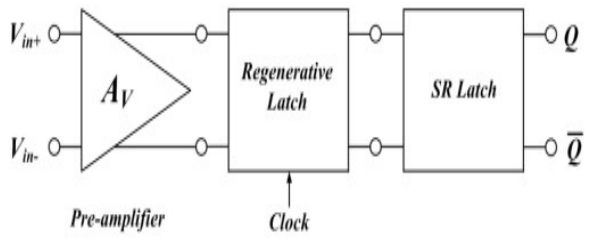

Fig 1. Block diagram of Dynamic Comparator.[02]

In this paper, a Comparator has been analyzed which low power and high speed have compared to existing comparator. There are many types of comparators but Dynamic comparators with their low power are mostly used. It has set of back to back cross coupled inverters to convert a small input-voltage difference to a full scale digital level in a short duration. This paper is divided into six sections. In section-II Conventional Dynamic comparators have been described. Section-III Lewis Comparator, Section- IV Resistor Divider Comparators, Section-V Simulation result, Section-VI Conclusion and Reference. 


\section{CONVECTIONAL DYNAMIC COMPARATOR}

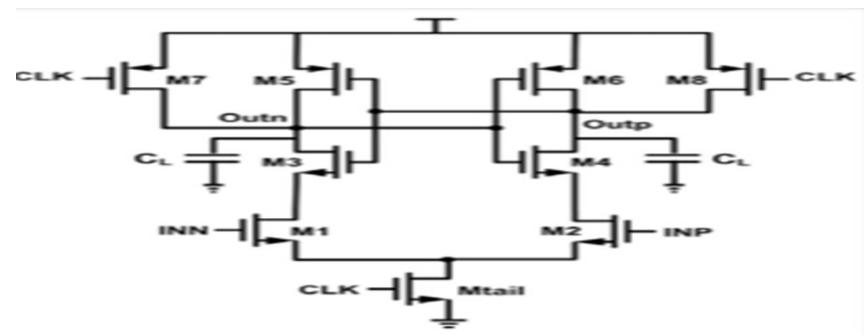

Fig 2.Conventional Dynamic Comparator [03]

The conventional dynamic comparator shown in above fig. 2 is mostly used in analog and digital converters. When $C L K=0$. Called reset phase the transistor $M_{\text {tail }}$ will be off. The transistors M5 and M6 which are called reset transistors becomes on and makes the output nodes "outp" and 'outn' to turn into level VDD for beginning of a start condition. When CLK becomes VDD then the M5 and M6 transistors are off, and Mtail becomes on then the output voltages (outp and outn), which where at VDD start to fall with different rates based on the corresponding discharging rates. Assume the case where the voltage VINP is greater than VINN then the voltage at output node discharges faster than the voltage at Outn node. As the voltage at Outp node which is discharged by M2 transistor drain current then voltage goes down to VDD-Vthp before the voltage at Outn node which is discharged by M1 transistor drain current, accordingly M7 transistor becomes on. Thus, the back to back inverters start the latch generation and the voltage at outn node becomes VDD and the voltage level at out node falls down to ground. [03]

\section{LEWIS GRAY COMPARATOR}

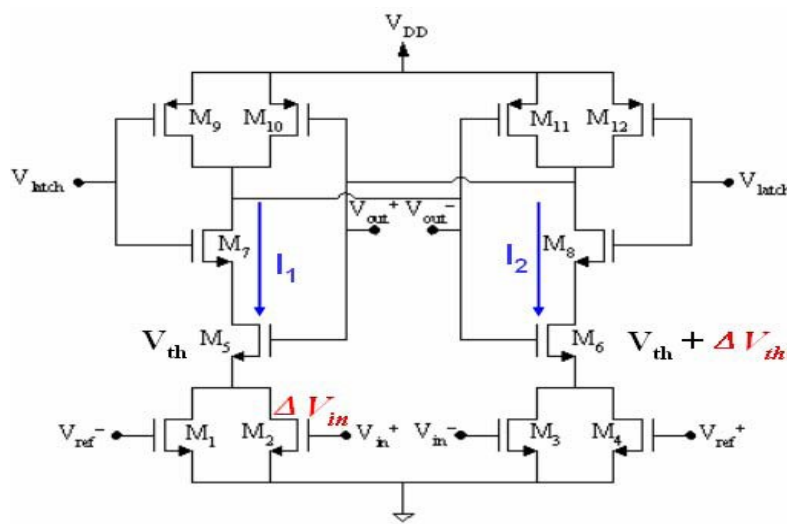

Fig 3. Lewis Gray Comparator [05]

In this structure (Fig.3) of lewis gray comparator input is given through-NMOS M1-M4 which will work in Triode region. The Vin voltage will vary transconductance of M5 \& M6. PMOS M10, M11 are latch transistors. M9 \& M12 are used as reset latch by setting the Vds of M7 \& M8 to zero. Here drain current of M5 \& M6 determine final state when latch goes high. If no mismatch is present in the comparator then changes its output when the conductance of the left and right input branches are equal $g_{L}=g_{R}$. With the help of threshold voltages of M5 and M6. 


$$
\text { Vin }(\text { Threshold })=\frac{W B}{W A} \text { Wref }^{\prime}
$$

Where

$$
\begin{aligned}
& \mathrm{W}_{\mathrm{A}}=\mathrm{W}_{2}=\mathrm{W}_{3} \quad \mathrm{~W}_{\mathrm{B}}=\mathrm{W}_{1}=\mathrm{W}_{4} \\
& \mathrm{~V}_{\mathrm{IN}=\mathrm{V}_{\text {in } 1}-\mathrm{V}_{\text {in } 2}} \mathrm{~V}_{\text {ref }}=\mathrm{V}_{\text {ref1 }}-\mathrm{V}_{\text {ref2 }}
\end{aligned}
$$

In Evaluation phase $\mathrm{V}_{\text {latch }}=\mathrm{V}_{\mathrm{DD}}$ \& $\mathrm{M}_{10}$ and $\mathrm{M}_{11}$ both PMOS transistors have equal drain and gate voltage, which make them both work at saturation region. Transistors $M_{7}$ and $M_{8}$ work as switches in cross-coupled transistor pairs including $\mathrm{M}_{5} \mathrm{M}_{10}$ and $\mathrm{M}_{6} \mathrm{M}_{11}$. This all are turned on during comparison stage and also working in the triode region because of its high gate voltage $\mathrm{V}_{\mathrm{g} 7,8}=\mathrm{V}_{\mathrm{DD}}$. The drain voltage of $\mathrm{M}_{5}$ and $\mathrm{M}_{6}$ is pulled up closed to $\mathrm{V}_{\text {out }}$ or $\mathrm{V}_{\text {out- }}$ and works in saturation because switches $M_{7}$ and $M_{8}$ are in the triode region. Transistors $M_{9}$ and $M_{10}$ are both turned off because control signal $\mathrm{V}_{\text {latch }}$ is $\mathrm{V}_{\mathrm{DD}}$, which indicates that mismatch effects in $\mathrm{M}_{9}$ and $\mathrm{M}_{12}$ is negligible [05].

\section{RESISTER DIVIDER COMPARATOR}

As shown in Fig, 4 is called Resister divider comparator because the input pairs (M1-M4) operate in linear region and adjust the trip point of the comparator resistively by means of

$$
\operatorname{Vin} 1-\operatorname{Vin} 2=\frac{B 1}{B 2}(\text { Wref1 }- \text { Vref2 })
$$

Where

$$
\begin{aligned}
& \mathrm{B} 1=\mu \mathrm{nCoxW} 1 / \mathrm{L} 1=\mu \mathrm{nCoxW} 2 / \mathrm{L} 2 \\
& \mathrm{~B} 2=\mu \mathrm{nCoxW} / \mathrm{L} 3=\mu \mathrm{nCoxW} 4 / \mathrm{L} 4
\end{aligned}
$$

This comparator is widely used because of its low kickback noise and simple relationship between input voltage and reference voltage as expressed in equation-(02). Additionally input can be as low as threshold voltage, Vthn and there for it can be used in low supply voltage. However, since M1- M4 are in deep linear region. The input referred offset is sensitive to the device mismatch of M1- M4 and M5- M6.This type of circuit will have more offset. [04]

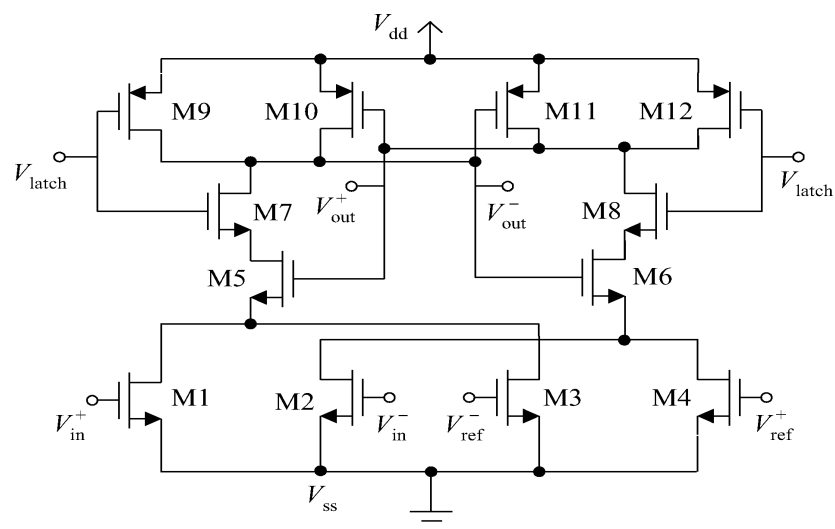

Fig 4.Resister Divider [04] 


\section{SIMULATION AND RESULT}

(1) The simulation of the above three dynamic comparators is done using 180nm TSMC and $90 \mathrm{~nm}$ Generic technologies. The supply voltages used are $0.5 \mathrm{~V}$ for $90 \mathrm{~nm}$ and $1.8 \mathrm{~V}$ for $180 \mathrm{~nm}$ technology as shown in Table II.

(2) Transistor dimensions are presented in Table III. Table. I.A\&B shows the comparator performance in terms of Propagation delay, offset voltage, ICMR and speed, slew rate etc. for $90 \mathrm{~nm} \& 180 \mathrm{~nm}$.

(3) For Simulation I have used Tanner Tools Version 13.00, with the help of S-Edit v13.00 TSpice v13.00 and W-Edit v13.00 applications.

(4) Simulated Output waveforms of Conventional dynamic comparator, Resistor Divider and Lewis gray comparators are illustrate in Fig .5, Fig.7 and Fig.9.with their input pulses using Generic 90nm Technology.Fig.No.6,8\&10shows the offset voltages of Conventional dynamic comparator, Resistor Divider and Lewis gray comparators simulated using Generic $90 \mathrm{~nm}$ technology. There values are mentioned in Table I.B.

\begin{tabular}{|l|l|l|l|}
\hline \multirow{2}{*}{ Parameter } & $\begin{array}{l}\text { Lewis Gray } \\
\text { Comparator }\end{array}$ & $\begin{array}{l}\text { Simple } \\
\text { Dynamic } \\
\text { Comparator }\end{array}$ & $\begin{array}{l}\text { Resistive } \\
\text { Comparator }\end{array}$ \\
\cline { 2 - 4 } & $\mathbf{1 8 0} \mathbf{~ n m}$ & $\mathbf{1 8 0} \mathbf{n m}$ & $\mathbf{1 8 0} \mathbf{~ n m}$ \\
\hline $\begin{array}{l}\text { Propagation } \\
\text { Delay (ns) }\end{array}$ & $2.01 \mathrm{~ns}$ & $2.55 \mathrm{~ns}$ & $2.03 \mathrm{~ns}$ \\
\hline ICMR & $\begin{array}{c}1.54 \mathrm{~V} \text { to } \\
1.64 \mathrm{~V}\end{array}$ & $\begin{array}{c}-1.75 \mathrm{~V} \text { to } \\
1.60 \mathrm{~V}\end{array}$ & $\begin{array}{c}1.79990 \mathrm{~V} \\
\text { to } 1.79980 \\
\mathrm{~V}\end{array}$ \\
\hline $\begin{array}{l}\text { Offset } \\
\text { Voltage } \\
(\mathrm{mV})\end{array}$ & $260.08 \mathrm{mv}$ & $942.46 \mathrm{mv}$ & $1.14 \mathrm{~V}$ \\
\hline Slew rate & $79.35 \mathrm{mv} / \mathrm{ns}$ & $3.37 \mathrm{mv} / \mathrm{ns}$ & $10 \mu \mathrm{v} / \mathrm{ns}$ \\
\hline Speed & $50 \mathrm{MHz}$ & $390 \mathrm{MHz}$ & $50 \mathrm{MHz}$ \\
\hline
\end{tabular}

Table I.A Comparative Analysis of above circuits.

\begin{tabular}{|l|l|l|l|}
\hline \multirow{2}{*}{ Parameter } & $\begin{array}{l}\text { Lewis Gray } \\
\text { Comparator }\end{array}$ & $\begin{array}{l}\text { Simple } \\
\text { Dynamic } \\
\text { Comparator }\end{array}$ & $\begin{array}{l}\text { Resistive } \\
\text { Comparator }\end{array}$ \\
\cline { 2 - 4 } & $\mathbf{9 0} \mathbf{~ n m}$ & $\mathbf{9 0} \mathbf{n m}$ & $\mathbf{9 0} \mathbf{n m}$ \\
\hline $\begin{array}{l}\text { Propagation } \\
\text { Delay (ns) }\end{array}$ & $1.55 \mathrm{~ns}$ & $1.8 \mathrm{~ns}$ & $1.8 \mathrm{~ns}$ \\
\hline ICMR & $\begin{array}{l}492.42 \mathrm{mV} \\
\text { to } 492.36 \\
\mathrm{mV}\end{array}$ & $-0.5 \mathrm{~V}$ to $0.5 \mathrm{~V}$ & $\begin{array}{l}484.90 \mathrm{mV} \text { to } \\
497.49 \mathrm{mV}\end{array}$ \\
\hline $\begin{array}{l}\text { Offset } \\
\text { Voltage }(\mathrm{mV})\end{array}$ & $150.62 \mathrm{mV}$ & $152.41 \mathrm{mV}$ & $331.72 \mathrm{mV}$ \\
\hline Slew rate & $943.98 \mathrm{mV} / \mathrm{ns}$ & $\begin{array}{l}955.59 \\
\mathrm{mV} / \mathrm{ns}\end{array}$ & $\begin{array}{l}991.76 \\
\mathrm{mV} / \mathrm{ns}\end{array}$ \\
\hline Speed & $640 \mathrm{MHz}$ & $150 \mathrm{MHz}$ & $550 \mathrm{MHz}$ \\
\hline
\end{tabular}

Table I.B Comparative Analysis of above circuits. 
International Journal of Microelectronics Engineering (IJME), Vol.2, No.2,April 2016

\begin{tabular}{|l|l|l|}
\hline \multirow{2}{*}{$\begin{array}{l}\text { Voltage } \\
\text { Terminals }\end{array}$} & \multicolumn{2}{|l|}{ Technology } \\
\cline { 2 - 3 } & $\mathbf{1 8 0 n m}$ & $\mathbf{9 0 n m}$ \\
\hline $\mathrm{V}_{\mathrm{DD}}$ & $1.8 \mathrm{~V}$ & $5 \mathrm{~V}$ \\
\hline $\mathrm{V}$ Ss & $-1.8 \mathrm{~V}$ & $-5 \mathrm{~V}$ \\
\hline $\mathrm{V}_{\mathrm{IN}+}$ & $1.8 \mathrm{~V}$ & 0.5 \\
\hline $\mathrm{V}_{\mathrm{IN}-}$ & $-1.8 \mathrm{~V}$ & -0.5 \\
\hline $\mathrm{V}_{\text {latch }}$ & $0.9 \mathrm{~V}$ & $0.1 \mathrm{~V}$ \\
\hline Vref $_{ \pm}$ & $\pm 0.5 \mathrm{~V}$ & $\pm 0.1 \mathrm{~V}$ \\
\hline
\end{tabular}

Table II.Voltage level used during simulation for above circuits.

\begin{tabular}{|l|l|l|l|}
\hline $\begin{array}{l}\text { Types of } \\
\text { Circuits/ } \\
\text { Transistor }\end{array}$ & $\begin{array}{l}\text { Lewis } \\
\text { Gray }\end{array}$ & $\begin{array}{l}\text { Simple } \\
\text { Dynamic }\end{array}$ & $\begin{array}{l}\text { Resister } \\
\text { Divider }\end{array}$ \\
\hline & $180 \mathrm{~nm}$ & $180 \mathrm{~nm}$ & $180 \mathrm{~nm}$ \\
\hline M1 & $\mathrm{N}-10 \mathrm{u}$ & $\mathrm{N}-03 \mathrm{u}$ & $\mathrm{N}-10 \mathrm{u}$ \\
\hline M2 & $\mathrm{N}-10 \mathrm{u}$ & $\mathrm{N}-03 \mathrm{u}$ & $\mathrm{N}-10 \mathrm{u}$ \\
\hline M3 & $\mathrm{N}-10 \mathrm{u}$ & $\mathrm{N}-03 \mathrm{u}$ & $\mathrm{N}-10 \mathrm{u}$ \\
\hline M4 & $\mathrm{N}-10 \mathrm{u}$ & $\mathrm{N}-03 \mathrm{u}$ & $\mathrm{N}-4 \mathrm{u}$ \\
\hline M5 & $\mathrm{N}-06 \mathrm{u}$ & $\mathrm{P}-03 \mathrm{u}$ & $\mathrm{N}-5.5 \mathrm{u}$ \\
\hline M6 & $\mathrm{N}-06 \mathrm{u}$ & $\mathrm{P}-03 \mathrm{u}$ & $\mathrm{N}-5.5 \mathrm{u}$ \\
\hline M7 & $\mathrm{N}-03 \mathrm{u}$ & $\mathrm{P}-05 \mathrm{u}$ & $\mathrm{N}-5.5 \mathrm{u}$ \\
\hline M8 & $\mathrm{N}-03 \mathrm{u}$ & $\mathrm{P}-05 \mathrm{u}$ & $\mathrm{N}-5.5 \mathrm{u}$ \\
\hline M9 & $\mathrm{P}-5.5 \mathrm{u}$ & $\mathrm{N}-2.5 \mathrm{u}$ & $\mathrm{P}-15 \mathrm{u}$ \\
\hline M10 & $\mathrm{P}-2.5 \mathrm{u}$ & $\mathrm{X}$ & $\mathrm{P}-10 \mathrm{u}$ \\
\hline M11 & $\mathrm{P}-2.5 \mathrm{u}$ & $\mathrm{X}$ & $\mathrm{P}-10 \mathrm{u}$ \\
\hline M12 & $\mathrm{P}-5.5 \mathrm{u}$ & $\mathrm{X}$ & $\mathrm{P}-15 \mathrm{u}$ \\
\hline
\end{tabular}

Table III-A Transistor Dimension

\begin{tabular}{|l|l|l|l|}
\hline $\begin{array}{l}\text { Types of } \\
\text { circuits/ } \\
\text { Transistor }\end{array}$ & $\begin{array}{l}\text { Lewis } \\
\text { Gray }\end{array}$ & $\begin{array}{l}\text { Simple } \\
\text { Dynamic }\end{array}$ & $\begin{array}{l}\text { Resister } \\
\text { Divider }\end{array}$ \\
\hline & $\mathbf{9 0 n m}$ & $\mathbf{9 0 n m}$ & $\mathbf{9 0 n m}$ \\
\hline M1 & N-3.5u & N-2u & N-2u \\
\hline M2 & N-3.5u & N-2u & N-2u \\
\hline M3 & N-1.5u & N-2u & N-2u \\
\hline M4 & N-1.5u & N-2u & N-2u \\
\hline M5 & N-2u & P-2u & N-3u \\
\hline M6 & N-2u & P-2u & N-3u \\
\hline M7 & N-2u & P-3u & N-3u \\
\hline M8 & N-2u & P-3u & N-3u \\
\hline M9 & P-3.5u & N-3u & P-5.5u \\
\hline M10 & P-15u & X & P-2.5u \\
\hline M11 & P-15u & X & P-2.5u \\
\hline M12 & P-3.5u & X & P-5.5u \\
\hline
\end{tabular}

Table III-B.Transistor Dimensions 
International Journal of Microelectronics Engineering (IJME), Vol.2, No.2,April 2016

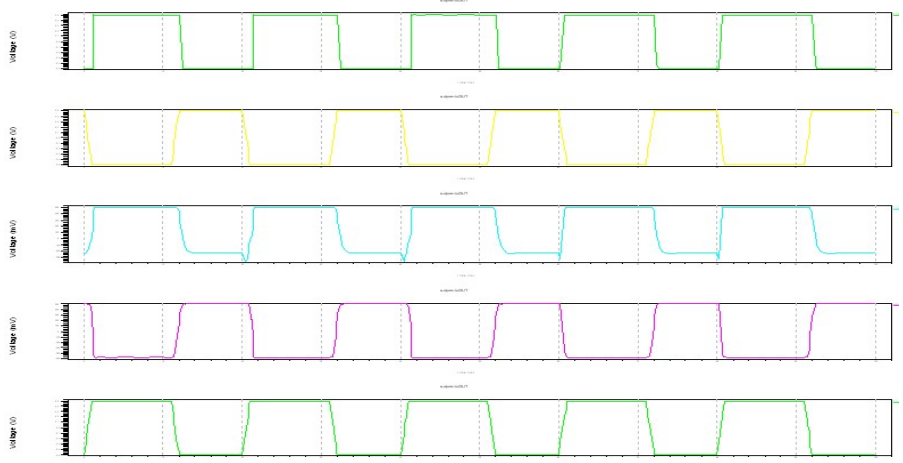

Fig.5 output waveform of Convectional dynamic comparator simulated using 90nm.

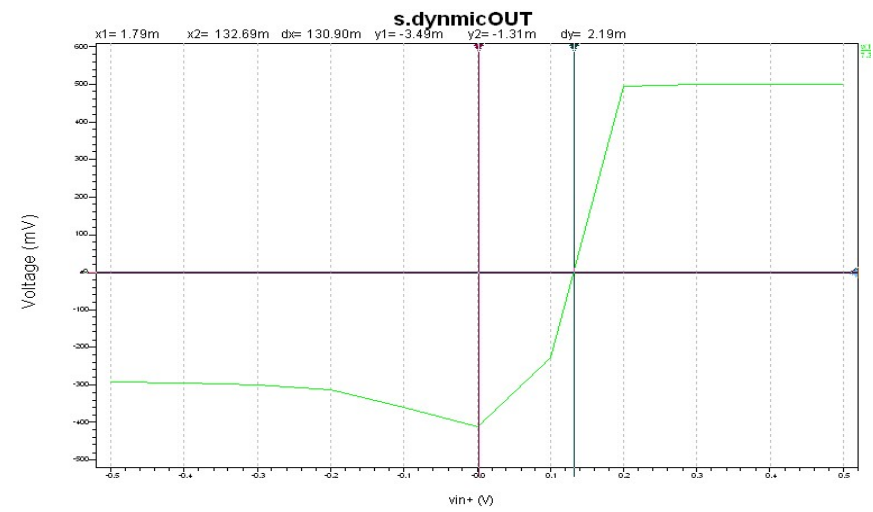

Fig.6. offset voltage of Convectional dynamic comparator simulated using 90nm.

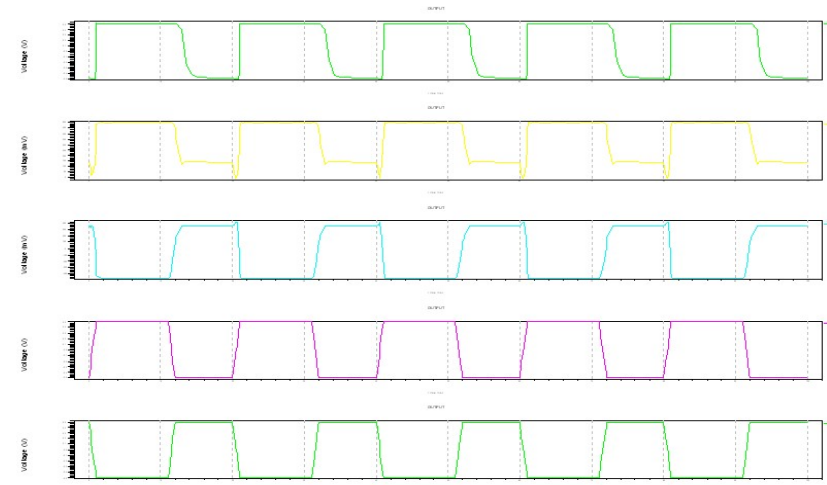

Fig.7.Resistive Divider comparator output waveform simulated using 90nm. 
International Journal of Microelectronics Engineering (IJME), Vol.2, No.2,April 2016

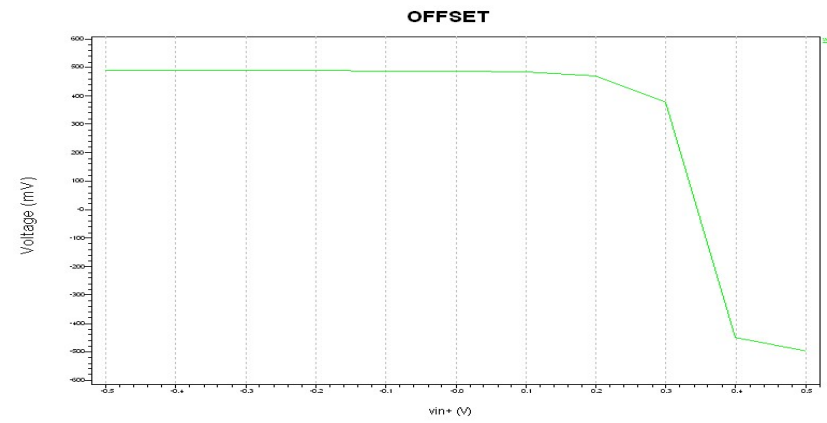

Fig .8. Resistive Divider comparator Offset voltage simulated using 90nm.

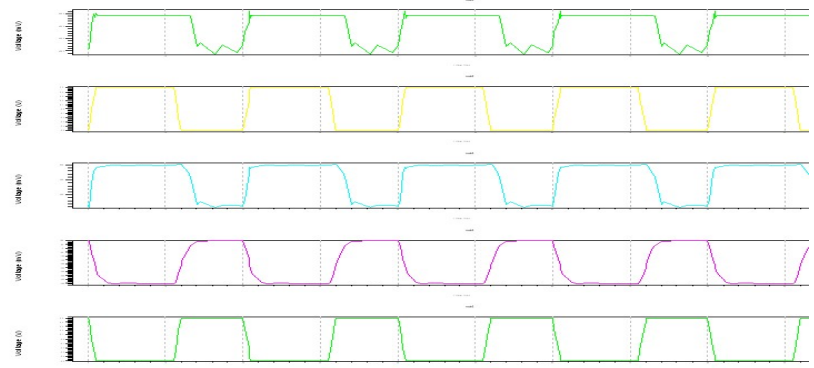

Fig.9.Lewis gray comparator output waveform simulated using $90 \mathrm{~nm}$.

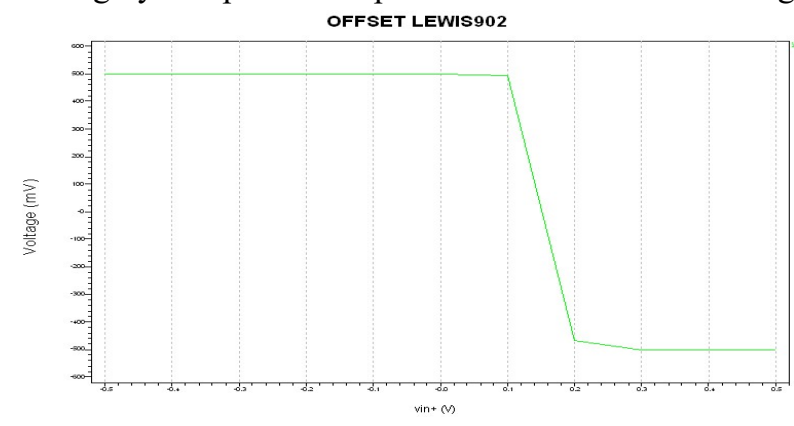

Fig.10. Lewis gray comparator offset voltage simulated using $90 \mathrm{~nm}$.

\section{CONCLUSION}

I conclude that Dynamic comparator can used to obtain low power and high speed CMOS comparator. Also found that with reduction of technology and optimizing the circuit can be obtained which low power, low offset and high speed CMOS voltage comparator. After comparing result of $180 \mathrm{~nm}$ with $90 \mathrm{~nm}$ dynamic comparators results are better for $90 \mathrm{~nm}$ technology. Out of three comparators result of conventional dynamic comparator is better as shown in Table I. 
International Journal of Microelectronics Engineering (IJME), Vol.2, No.2,April 2016

\section{References:}

1. R. Jacob Baker, Harry W. Li, David E. Boyce, "CMOS Circuit Design,

2. Douglas R. Holberg, "CMOS Analog Circuit Design ,”Oxford University Press, Second Edition, 2002.

3. "Analysis and Design of a Low-Voltage Low-Power Double-Tail Comparator" paper by Samaneh Babayan- Mashhadi, Student Member, IEEE, and Reza Lotfi, Member, IEEE.2014.

4. "A novel low offset Dynamic Comparator for high speed low voltage pipe line ADC" a paper by jinda yang, Xu cheng, Zhang zhang Fudan university shanghai 201203 china.

5. "A Simple and Accurate Method to Predict Offset Voltage in Dynamic Comparators" a paper by Jun He and Sanyi Zhan Department of Electrical and Computer Engineering Iowa State University Ames, IA 50011, USA 